Esta revista forma parte del acervo de la Biblioteca Jurídica Virtual del Instituto de Investigaciones Jurídicas de la UNAM www.juridicas.unam.mx

\title{
Contenido y estructura de la publicidad política televisiva en el proceso electoral federal 2012
}

\author{
Julio Juárez Gámiz \\ José Antonio Brambila
}

Sumario:

I. Introducción

II. Ausencia de información política en campañas electorales

III. Mucha promoción, poca información

IV. Personalización de la política

V. Emotividad y racionalidad en las campañas

VI. Partidos como argumento persuasivo

VII. Conclusiones

VIII. Bibliografía 


\section{Introducción}

En época electoral la publicidad política en medios masivos de comunicación representa una importante fuente de información política para la ciudadanía. Al menos desde una perspectiva teórica. Veamos algunos datos a manera de contexto. En el caso mexicano una parte importante del electorado (57\%) sigue con atención la campaña electoral y $42 \%$ dice prestar atención a la publicidad que los partidos políticos trasmiten a través de la radio y la televisión. Más de la mitad (60\%) asegura recordar dicha publicidad. ${ }^{1}$ No es de extrañar, por tanto, que la legislación electoral intervenga de manera directa en la manera en la cual los partidos políticos acceden a la radio y la televisión mediante un formato predominantemente publicitario.

La presente investigación tiene como objetivo analizar el contenido y estructura de la publicidad política televisiva producida por los partidos durante el proceso electoral federal de $2012 .^{2}$ Los hallazgos presentados se evalúan a la luz de los cambios estructurales y de contenido que, directa o indirectamente, estarían asociados a la reforma electoral 2007-2008.

Respecto a la publicidad política, la reforma electoral modificó los artículos 56 y 58 del Código Federal de Instituciones y Procedimientos Electorales para establecer que la transmisión de los mensajes de los partidos se realizaría dentro de un esquema de distribución del tiempo fiscal dejando fuera el papel del dinero en la contratación de espacios en radio y televisión. El principal criterio de la reforma fue privilegiar la equidad por encima de la libertad de contratación de los partidos políticos.

Es así como en la actualidad la autoridad electoral administra, durante el periodo electoral, 48 minutos por canal de televisión y estacion radiofónica, ${ }^{3}$ que distribuye de la siguiente manera: 41 minutos

1 Posicionamiento público del Instituto Federal Electoral. Resultados de la encuesta poselectoral realizada por el Centro de Investigación y Docencia Económicas (CIDE), 13 de octubre de 2009, pp. 68-70.

2 La información presentada en este artículo se basa en un análisis de los spots que los siete partidos políticos produjeron durante la elección federal de 2012. A cada spot se aplicó un protocolo de 47 variables (de contenido y estructura).

${ }^{3}$ Con un máximo de tres minutos por hora de transmisión entre las 06:00 a las 24:00 horas. 
entre los partidos políticos y 7 minutos son destinados "para los fines propios del Instituto y de otras autoridades electorales". Es importante señalar que a pesar de que la legislación (artículo 56 del Cofipe) contempla la transmisión de spots de 30 segundos, uno y dos minutos, los spots producidos por los partidos políticos durante el proceso Federal Electoral de 2012 son de 30 segundos tal y como lo estableció el Comité de Radio y Televisión del IFE (ACRT/028/2011).

De acuerdo con el artículo 56 del Cofipe, el IFE reparte el tiempo aire disponible para los partidos políticos en apego a un criterio que otorga $30 \%$ de manera equitativa y $70 \%$ de acuerdo al porcentaje de votación obtenido en la elección inmediata anterior para diputados federales. La producción de los mensajes corre a cargo del partido político y la única razón que impediría la transmisión de un mensaje ex ante serían deficiencias técnicas que, al momento de ingresar al pautado, detectara el propio Instituto.

Respecto al contenido de la publicidad política, la reforma electoral 2007-2008 llevó a la Constitución la prohibición a la calumnia de personas o denigración de instituciones antes únicamente considerada en el Cofipe. De acuerdo al artículo 41 (inciso III, apartado C) constitucional, "(en la propaganda) que difundan los partidos deberán abstenerse de expresiones que denigren a las instituciones y a los propios partidos, o que calumnien a las personas".

En cuanto a los spots que se analizan en este artículo, se toman en consideración los 308 mensajes (ejecuciones) producidos por los siete partidos políticos durante el proceso federal de $2012^{4}$ (véase figura 1). Por tanto, el presente trabajo se basa en un censo de spots para las campañas presidencial y al Congreso de la Unión.

4 Los spots que se analizan aquí fueron descargados de la página de pautas del IFE (http://pautas.ife.org.mx/), del 30 de marzo al 27 de junio de 2012. 


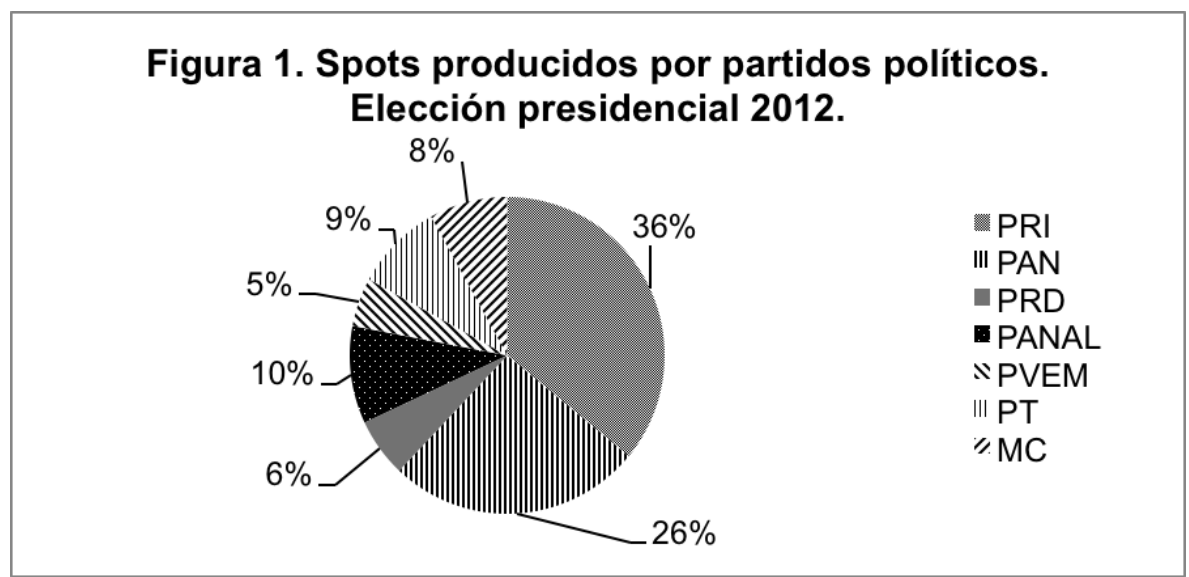

Fuente: elaboración propia.

Como lo ilustra la figura 1, las ejecuciones analizadas están distribuidas de la siguiente manera: del Partido Acción Nacional (PAN) se registraron 81 (26\% del total); del Partido Revolucionario Institucional (PRI), 111 (36\%); Partido de la Revolución Democrática (PRD), 18 (6\%); Partido del Trabajo (PT), 27 (9\%); Partido Verde Ecologista de México (PVEM), 16 (5\%); Movimiento Ciudadano (MC), 24 (8\%), y Partido Nueva Alianza (Panal), $31(10 \%) .^{5}$

En suma, este artículo analiza el contenido y la estructura de la publicidad televisiva que los partidos políticos producen y difunden a través del tiempo oficial. El principal objetivo del estudio es evaluar la oferta informativa de una de las principales herramientas de comunicación en el actual modelo de comunicación política. Dicha evaluación se construye a partir de dos nociones sustantivas para la democracia mexicana. A saber, la rendición de cuentas y la transparencia en la utilización de un bien público, el tiempo oficial, que tiene como principal propósito y justificación la provisión de información que enriquezca la toma de decisiones del electorado mexicano y motive la reflexión y el intercambio de ideas sobre distintos proyectos de gobierno. No está de más subrayar que dichos materiales publicitarios están financiados por el Estado mexicano, tanto en su producción

5 Los hallazgos del estudio se presentan por partido político y no por coalición. Lo anterior responde, entre otras cosas, a que a partir de la reforma electoral de 2007-2008, los partidos políticos, estén o no coaligados, deberán captar los votos del electorado de forma individual y no, como sucedía anteriormente, por coalición política. 
como en su difusión, con miras a promover una cultura democrática y elevar así el debate propio de una democracia funcional y competitiva.

El artículo está dividido en seis apartados temáticos que provienen tanto de la investigación acerca del efecto de la publicidad en el electorado así como de una perspectiva normativa en concordancia con los motivos que fundan el actual modelo de comunicación. Estos apartados resumen también las principales conclusiones de la Observación Electoral que realizara el Centro de Investigaciones Interdisciplinarias en Ciencias y Humanidades de la UNAM acerca de la publicidad política mediante el financiamiento del TEPJF, el IFE, la Segob, que administrara el Programa de las Naciones Unidas para el Desarrollo. Estos apartados son: 1. Ausencia de información política en la publicidad política. 2. Promoción, negatividad y contraste en los spots políticos. 3. Personalización de la política. 4. Emotividad y racionalidad. 5. Estrategia a partir de contenidos. Al final se presentan las principales recomendaciones de la investigación.

\section{AUSENCIA DE INFORMACIÓN POLÍTICA EN CAMPAÑAS ELECTORALES}

De acuerdo con el artículo 41 de la Constitución Política de los Estados Unidos Mexicanos, los partidos políticos "tienen como fin promover la participación del pueblo en la vida democrática... de acuerdo con los programas, principios e ideas que postulan”. Para ello el Estado los provee de prerrogativas que faciliten la consecución de los objetivos antes mencionados, entre dichas prerrogativas está el acceso a los medios masivos de comunicación (radio y televisión). Por tanto, los partidos tienen la obligación de difundir sus plataformas electorales, para así fomentar la participación electoral de los ciudadanos.

Siguiendo esta idea, para la presente investigación se extrajeron los seis principales grupos temáticos (clusters) que los siete partidos políticos desarrollaron en la plataforma electoral que registraron ante el IFE antes de la campaña (véase tabla 1), éstos son: 1) reforma del Estado; 2) seguridad; 3) política social; 4) economía; 5) política exterior, y 6) medio ambiente. Además de estos seis clusters temáticos, en la investigación se incluyó otro más que fue definido como "estrategia electoral", es decir, spots cuyo tema principal no fuera ninguno de los 
seis anteriores, sino la presentación de acciones mediáticas planificadas con el objetivo de lograr un fin meramente electoral (quitar votos, mantener registro, comparar o atacar a los rivales, promover símbolos, valores y personas, entre otros) ${ }^{6}$

Como se observa en la tabla 1 , los resultados del estudio muestran que el cluster de "estrategias electorales" fue el más utilizado por todos los partidos políticos con $55.5 \%$ de los spots, seguido por "seguridad pública" con $14.6 \%$ de las producciones, "política social” con 13.6\%, y "economía" con 13\%. Los temas incluidos dentro de los grupos "reforma del Estado", "política ambiental” y "política exterior” fueron los menos tratados por los partidos.

De acuerdo con nuestra investigación, más de la mitad de los mensajes dejaron de lado las propuestas y soluciones a los problemas nacionales, ${ }^{7}$ pues se centraron en mensajes insustanciales o autorreferenciales, en ataques y descalificaciones, en vez de ofrecer información política de utilidad para el electorado. Del total de spots que utilizaron "estrategia electoral", la mayoría de las veces (35\%) fueron catalogados como "estrategia-contexto", es decir, spots con temas referentes al uso de factores y circunstancias que ocurren durante la campaña electoral sobre candidatos y partidos que participan en ella (escándalos, declaraciones, protestas, etcétera).

6 Cabe resaltar que cada una de estas siete categorías temáticas (las seis extraídas de las plataformas electorales más "estrategia electoral") son mutuamente excluyentes, es decir, un mismo spot no fue codificado a la vez como de "seguridad" o de "política social", sino solamente en una categoría.

7 En este se sentido, la evidencia empírica disponible apunta que para el electorado los partidos políticos utilizan la publicidad para criticar a sus oponentes (39\%), difundir sus propuestas (33\%) o ambas (22\%). CIDE, op. cit., p. 67. En otro estudio se determinó que para $62 \%$ del electorado, los spots han sido poco o nada útiles para definir su voto (Reforma, 6 de mayo de 2012). 


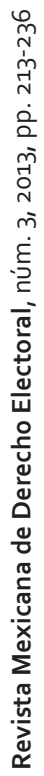

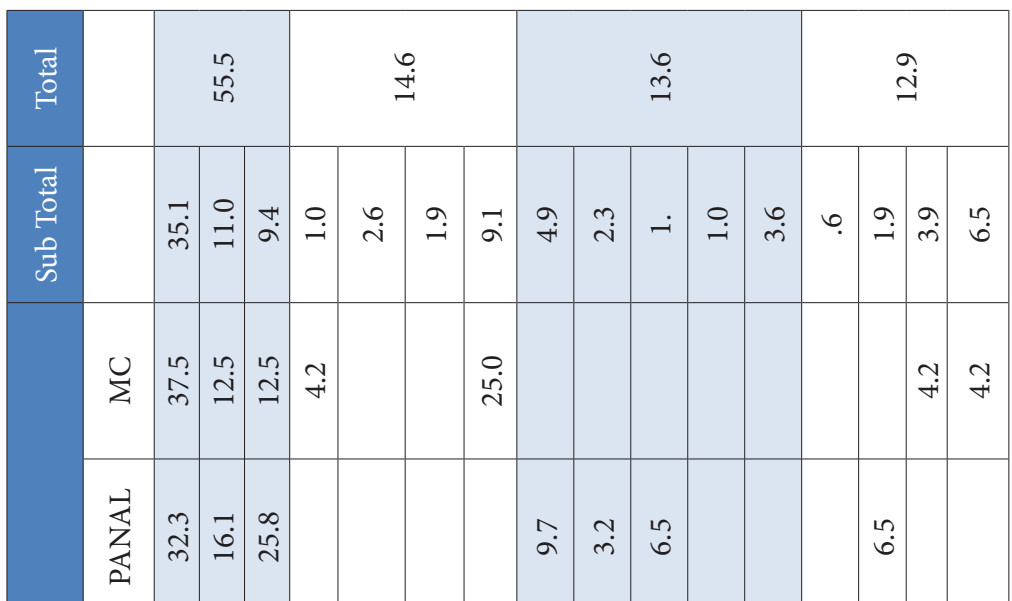

$n$
+
0
$n$
n
n

든

좀

몸

$\frac{\alpha}{n}$

¿্ঠ

은

บ

는 원

든

ำ

언

-

है

$\pm$

के

$+$

ป 는

ㅎํㅁ

ํำ

d $\frac{2}{n}$

은

บ $\frac{1}{4}$

궁

응

ช

$\frac{0}{\sigma}$

它

U

능

हี

站

๓ु. $\frac{m}{m}$

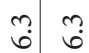

तं

$\frac{\pi}{\frac{0}{0}}$

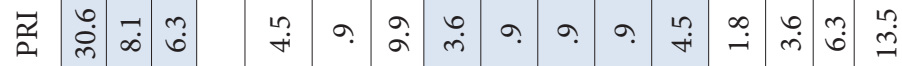

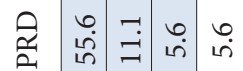

$\stackrel{-}{=}$

Z

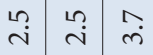

$\dot{n}$

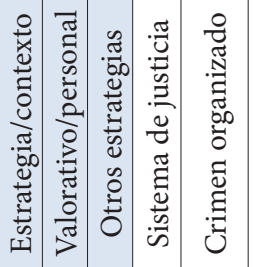

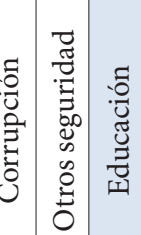

ڤ్ర

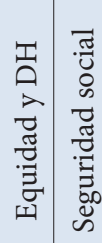

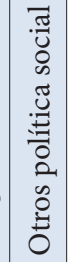

ก.

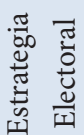

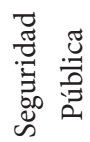

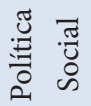

킁 


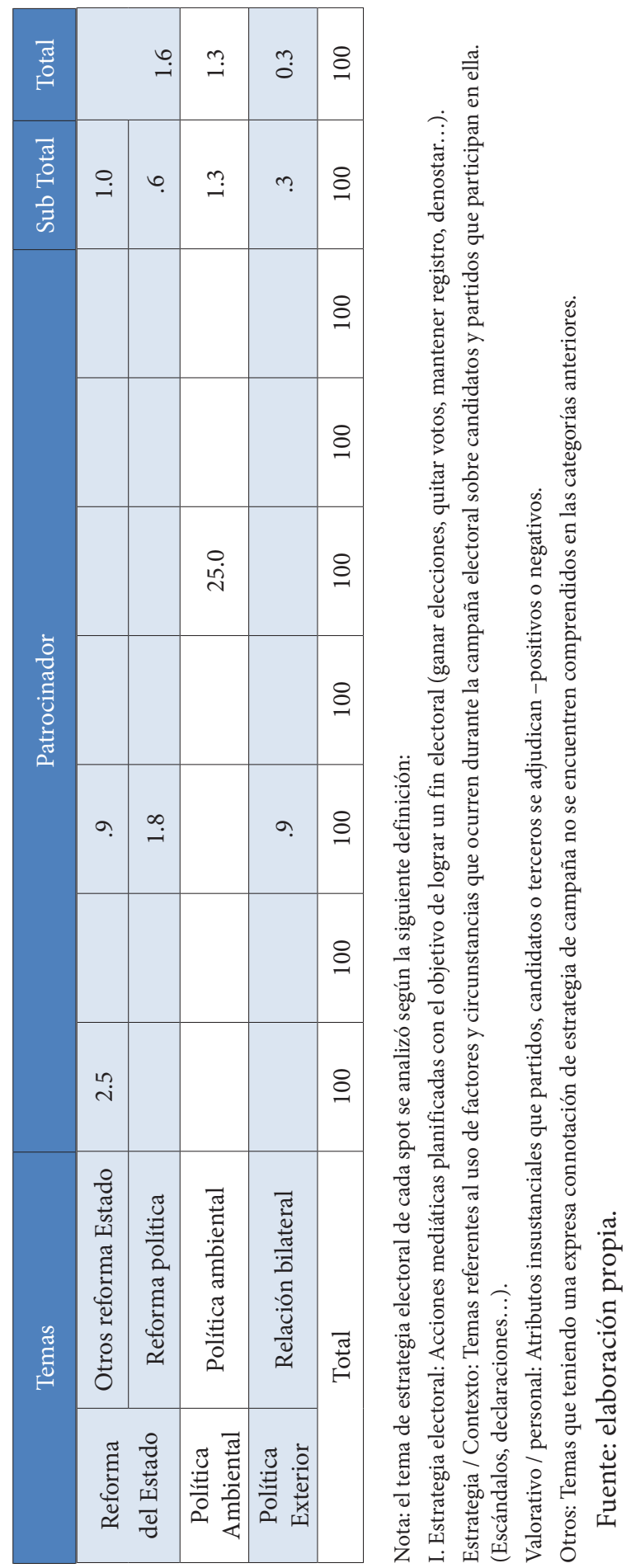


Los partidos políticos que más recurrieron a esta categoría fueron: el PRD, 56\%; el PT con igual porcentaje de sus spots dedicados a este rubro, y el PAN, 35\%. El partido que usó menos la "Estrategia-Contexto" fue el PVEM (solamente 12.5\%), en contraste con los demás partidos dicho instituto político ocupó buena parte de su spots para presentar propuestas específicas.

Como se observa en la tabla 1, el otro subtema del cluster "estrategia-electoral" es el "valorativo-personal": atributos insustanciales que partidos, candidatos o terceros se adjudican - positivos- o asocian a sus oponentes - negativos-. El PAN utilizó más veces este tipo de spots (17\%). La estrategia del partido intentó posicionar a la candidata por medio de sus atributos personales. Desde el inicio de la campaña, Josefina Vázquez Mota se presentó como una candidata distinta de sus contrincantes, dicha distinción se anclaba en características insustanciales y autorreferenciales carentes de una argumentación clara ("Josefina Diferente"), o en la referencia a su condición de género ("Josefina. La mujer tiene palabra").

El resto de los spots publicitarios (46\%) está distribuido entre los seis grupos temáticos arriba mencionados. Durante la elección cada uno de los siete partidos políticos se "apropió" de uno de los seis tópicos. De acuerdo con la literatura, el éxito de la apropiación de un tema no se vincula solamente con la capacidad del candidato de asociarlo positivamente con su experiencia de gobierno, sino también con la capacidad de posicionar "su tema" en la agenda mediática (Ansolabehere e Inyegar, 1994).

Con la identificación de qué temas se apropió cada partido, es posible identificar por dónde dirigió su campaña electoral cada agrupación política: el PRI se identificó con "economía" (25.2\% de sus spots); la coalición de izquierda (MC en $29.2 \%$, PT en $25.9 \%$ y PRD en $16.7 \%$ ) con el de "seguridad"; el PVEM (50\%), el Panal (19.4\%) y el PAN (17.3\%) con el de "política social", y el PVEM con "política ambiental" (25\%).

"Economía" es el tema más importante entre la opinión pública $(R e$ forma, 1o. de mayo de 2012), por tanto, era de esperarse que dicho tema fuera capitalizado por algún partido político, en este caso el PRI. Quizás esta estrategia se hizo en alianza, pues el otro partido que postuló a EPN, el PVEM, también trató dicho tema (12.5\%). De hecho, el PRI también usó esta bandera en la elección federal de 2006 (41\%). 
La estrategia de la coalición de izquierda radicó en usar el tema de "seguridad", exaltando las fallas en dicha materia de la administración del presidente Felipe Calderón, pues se percibe entre la opinión pública, que el principal responsable de la seguridad pública es el gobierno federal y no son los gobiernos locales o estales (BGC-Excélsior, 23 de abril de 2012), buscando, de esta forma, posicionar en la agenda mediática una evaluación negativa para la administración panista.

Como se observa en la tabla 1, respecto al tema de "política social", el PVEM centró sus propuestas en una serie de promesas de políticas públicas como en el caso de promoción de vales de medicina y extinción de pago de cuotas en las escuelas (dedicando 50\% de sus spots a ello). Al referirse a las categorías de este bloque el Panal se distinguió por sus spots de "Educación" (9.7\%). Finalmente, aunque el PAN también centró sus spots en "política social” (17\%), también lo hizo con el tema de "educación" (8.6\%).

La "política ambiental" fue uno de los rubros menos recurridos por los partidos (1.3\%), no obstante, representa el $25 \%$ de los spots del PVEM. Finalmente, a los temas asociados con la "reforma del Estado" solamente se refirieron, de forma muy marginal, el PRI y el PAN, con $2.7 \%$ y $2.5 \%$, respectivamente. A "política exterior" solamente se refirió el PRI en un $0.9 \%$ de sus spots; es decir, un solo spot de toda la elección federal 2012 habló de la relación de México con el extranjero.

\section{Mucha promoción, poca información}

Durante el proceso electoral federal de 2012, los partidos políticos utilizaron más los spots de promoción que los de ataque y contraste (véase figura 2). De acuerdo con nuestro estudio, el 89\% de los spots se destina a promover al candidato o partido, las más de las veces con presentaciones discursivas unidireccionales en lugar de proposiciones que buscan un diálogo entre partidos políticos o con el electorado.

El partido que sólo promovió su imagen fue el PVEM, ocupando la totalidad de su tiempo para promoverse como entidad política. De hecho, en los spots que utilizaron el contraste para exponer una situación pública (por ejemplo falta de medicinas en las farmacias o el cobro de cuotas en las escuelas), este partido político no dirigió sus mensajes contra ningún actor político en particular. 
Figura 2. Proporción de spots de acuerdo con el contenido de sus

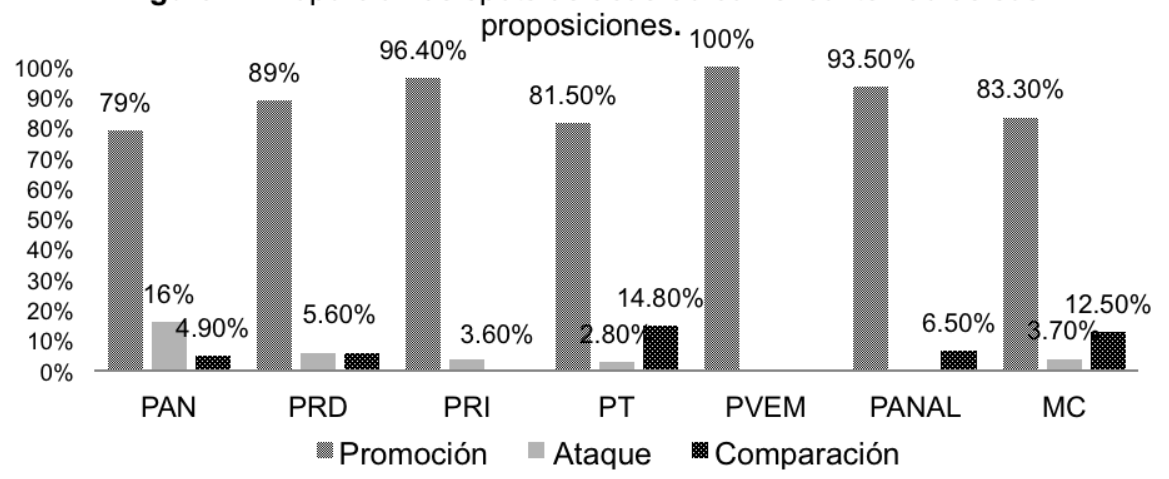

Fuente: elaboración propia.

Muy de lejos del número de spots que utilizan la promoción como estrategia del mensaje, los spots comparativos fueron los menos utilizados por los partidos políticos (4.5\%). El partido con más comparaciones fue el PT (14.8\%). Esto se debe, entre otras cosas, a que el PT buscó contrastar más la experiencia de gobierno de su candidato (AMLO) con la de sus oponentes. En 2006 también fue un partido de izquierda, el PRD, quien utilizó más comparaciones (4.7\%).

Los ataques representaron la segunda proposición más utilizada $(6.5 \%) .{ }^{8}$ El PAN fue el partido que más utilizó esta estrategia pues $16 \%$ de sus spots tenían este propósito. Tal magnitud, es notoriamente mayor al 5.6\% destinado por el PRD; el 3.6\% del PRI; el 3.7\% del PT y el $4.2 \%$ de MC. Los ataques hechos por el PAN se dirigieron más hacia los candidatos (84.6\%) que a los partidos políticos (15.6\%). Los ataques del PAN pueden explicarse como parte de los cambios que, en materia de preferencias electorales, se fueron dando durante la campaña, pasando del segundo al tercer lugar en las preferencias (Refor$m a, 31$ de mayo de 2012). Sus ataques se destinaron tanto al primero como al segundo lugar, ya fuera el PRI o el PRD.

8 En la literatura no hay consenso respecto a los efectos en el electorado del uso de spots negativos. Por un lado, algunos autores afirman que dichos spots tienden a disminuir el interés del electorado en la política y, por tanto, a acudir menos a las urnas (Ansolabehere e Inyegar, 1995). Por otro, hay una corriente crítica a esta posición y afirma que no hay relación entre el tono de la campaña y los resultados de la participación electoral, es decir, no encontraron evidencia concluyente sobre la desmovilización del electorado con este tipo de campaña (Freedman y Goldstein, 1999). 
Ahora bien, como se refleja en la tabla 2, los efectos restrictivos de la reforma electoral de 2007-2008, en donde se estableció la prohibición constitucional del uso de este tipo de campañas, se observan en la tendencia a disminuir los spots negativos en las campañas electorales en México. Mientras en 2006 dichos spots representaron el 27\% de la producción, en 2009 disminuyó a 10\%, y en 2012 alcanzaron solamente el $6.5 \%$.

Otra consecuencia de la reforma electoral de 2007-2008 estriba en la disminución de spots negativos centrados en la estrategia del miedo. En este sentido, cabe resaltar que a diferencia de 2006 (Treviño, 2009), en donde hubo uso (por parte de partidos y candidatos) así como resonancia (por parte de medios de comunicación) de campañas negativas centradas en el miedo, en 2012 los spots de ataque con fundamento en el miedo fueron mínimos (0.9\% del total).

Tabla 2.

Porcentaje de spots por proposición (promover, atacar y comparar) en elecciones federales de 2000, 2006, 2009 y 2012 en México

\begin{tabular}{|ccccc|}
\hline \multicolumn{5}{c}{ Campaña } \\
\hline Proposición/ Año & $2000^{*}$ & $2006^{*}$ & $2009^{\star}$ & $2012^{\star *}$ \\
\hline Promover & 85 & 68 & 84 & 89 \\
\hline Atacar & $\mathbf{1 3}$ & $\mathbf{2 7}$ & $\mathbf{1 0}$ & $\mathbf{6 . 5}$ \\
\hline Comparar & 2 & 4 & 6 & 4.5 \\
\hline Total & 100 & 100 & 100 & 100 \\
\hline
\end{tabular}

Nota: la proposición de cada spot se analizó según la siguiente definición:

Orientación de la proposición: la orientación significa la dirección hacia la cual apunta la proposición al momento de definir una situación en particular.

Promoción: identificación explícita de las cualidades del candidato o partido patrocinador

Ataque: referencia explícita en sentido negativo de las características profesionales y/o personales de uno o más oponentes.

Comparación: comparación entre el partido/candidato patrocinador del mensaje y uno o más de sus oponentes (nota: es necesaria la mención expresa de ambos).

${ }^{\star}$ Muestra de ejecuciones.

${ }^{* *}$ Censo de ejecuciones.

Fuente: elaboración propia. 
Esta prepondernacia promocional no se puede considerar como una mayor obtención de información para el electorado mexicano. Los spots fueron más positivos aunque, paradójicamente, carecieron de información detallada que abonara, tal y como lo establece la justificación legislativa a la obtención de esta prerrogativa, la discusión pública durante el proceso electoral.

\section{Personalización de la política}

La preponderancia en el contenido de los spots de la imagen de los candidatos a la Presidencia de la República en detrimento de los candidatos al Congreso es uno de los hallazgos más relevantes de esta investigación.

Aunque la legislación vigente (Cofipe, artículo 60) estipula que "en el proceso electoral en que se renueven el Poder Ejecutivo de la Unión y las dos Cámaras de Congreso, cada partido deberá destinar, al menos, un treinta por ciento de los mensajes a la campaña de uno de los poderes", en realidad no se puede apreciar con claridad el número de ejecuciones destinadas ya sea a candidatos presidenciales o al Congreso. Independientemente de si uno mira el contenido expreso del mensaje o la rúbrica insertada por el partido que lo produce.

Del total de los spots del censo se detectó en 250 (81\%) la presencia de alguno de los cuatro candidatos a la Presidencia. El resto de producciones, 58 (19\%), estuvieron destinadas a mensajes en donde los candidatos a la Presidencia no aparecían sin que esto significara que fueran destinados expresamente a las campañas de senadores o diputados.

De acuerdo a nuestra investigación, en el 27\% del total de los spots (85 de 308) apareció explícitamente una leyenda de llamado al voto para diputados y senadores (véase figura 3). Sin embargo, esto no significa que esos spots fueran dedicados a la promoción de los candidatos al Congreso, pues la gran mayoría se utilizó para promover la figura presidencial o para hacer campaña de ataque contra sus demás contrincantes. En suma, la presencia de rúbricas llamando a votar por diputados y senadores no significaba directamente que el contenido del spot hiciera referencia, en audio o en video, a los candidatos al 
Congreso. Paralelamente, muchos spots en donde se llamaba a votar por los candidatos al Congreso no aparecía rubricados.

Figura 3. Porcentaje intrapartidista de spots rubricados.

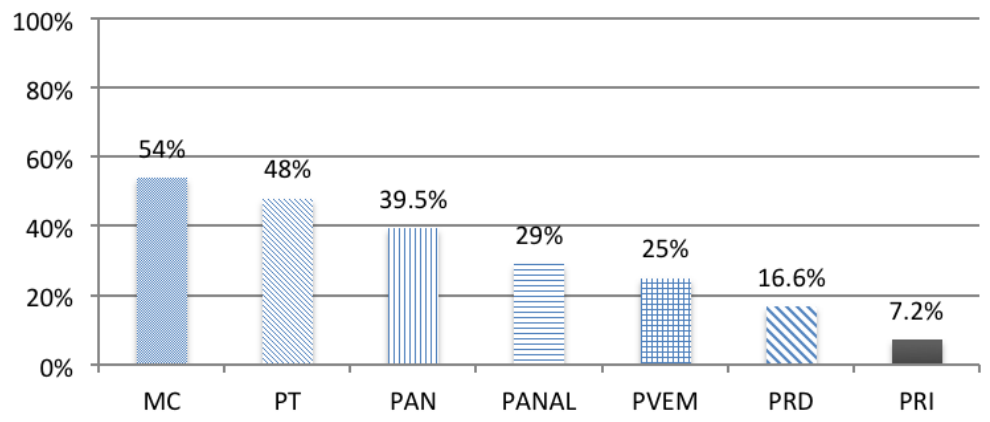

En la lógica de la personalización de la política, las características faciales de los candidatos se asocian con la calidad, seriedad o profesionalismo del mismo. De esta manera, dichas características sirven para evaluar cualidades o defectos de un individuo (i. e. confianza, firmeza, actitud, etcétera).

Durante la elección federal de 2012 se percibió la tendencia de los candidatos a presentar mayoritariamente características faciales de firmeza en un 59\%, seguido por una expresión contenta con un $26 \%$. En este sentido, los candidatos que aparecieron con una expresión facial de seriedad en un mayor número de spots fueron Andrés Manuel López Obrador, de la coalición de izquierda, y Enrique Peña Nieto, de la coalición PRI-PVEM.

El candidato de la coalición de izquierda apareció con un gesto de firmeza en un $40 \%$ de los spots patrocinados por el PRD, en el $50 \%$ de spots del PT y por último, en un 56\% de spots de MC. Lo anterior contrasta con las elecciones de 2006 en donde apareció con una expresión de contento en la mayoría de los casos ( $83 \%$ de los spots). Si bien consideramos que existen diversas razones que dan cuenta de lo anterior, aquí esbozaremos solamente algunas.

En 2006 el candidato de la izquierda mostró una expresión contenta asociada con la ventaja de poco más de 10 puntos sobre su más próximo competidor que mantuviera varios meses antes de que iniciara la elección (Juárez, 2007). En 2012, en contraste, la firmeza facial mostrada por López Obrador se relaciona con la intención de posicionarse 
en las preferencias del electorado, pues al inicio de la campaña, López Obrador contaba con una intención de voto del 22\%, a diferencia de Peña Nieto, quien tenía 45\% (Reforma, 22 de marzo de 2012). Sin embargo dicha tendencia fue transformándose conforme avanzaron las campañas; para el mes de mayo ambos candidatos se encontraban tan solo a 4 puntos porcentuales de diferencia (López Obrador, 34\%, y Peña Nieto, 38\%; Reforma, 31 de mayo de 2012).

Respecto a las características faciales mostradas por Peña Nieto, éstas se caracterizaron por ser firmes en un $65 \%$ de sus spots. Dicho porcentaje mantiene la tendencia de 2006, cuando el entonces candidato tricolor, Roberto Madrazo, apareció en $82 \%$ de los spots con expresiones faciales de firmeza. Probablemente en ambos casos los aspirantes del PRI tuvieron la intención de transmitir al electorado la imagen de un candidato asociado al orden.

Por su parte, Josefina Vázquez Mota del PAN tuvo más equilibrio en sus expresiones faciales, apareció $45 \%$ de las veces con una expresión firme y $38 \%$ de manera contenta, probablemente resultado del constante cambio de estrategia percibido en la producción de sus mensajes.

La personalización de la política también se observa en los formatos de producción que son utilizados, pues las más de las veces, sirven para explotar presuntas cualidades de los candidatos. De acuerdo a este estudio, como se puede apreciar en la tabla 3, el documental fue el formato más utilizado durante la elección de 2012 (46\%). ${ }^{9}$ Los documentales, además de presentar información sobre un tema determinado, sirven para difundir la imagen de un candidato, algo muy importante en un medio primordialmente visual. De acuerdo con nuestro estudio, este formato apareció presentado, principalmente, por políticos. Con esto los políticos recuperaron un papel significativo dentro de las campañas, su imagen fue más explotada que en las dos elecciones federales anteriores (2006 y 2009).

El PRI fue el partido que usó más este formato. En la mayoría de las ejecuciones aparecía su candidato, Enrique Peña Nieto, hablando de forma directa al televidente, como se hace en los talking heads, no obstante, durante su diálogo se introducian imágenes que ilustraban

9 Un formato narrativo en donde se presenta información respecto a un tema determinado y con la pretensión de utilizar dicha información como el elemento fundamental del mensaje. 
sus propuestas o sus argumentos. Los spots del PRI confiaron en la presentación por medio de imágenes de su candidato encuadrado en un marco de significado nacionalista como sitios turísticos o característicos del patrimonio cultural nacional.

Otro formato que favorece la personalización de la política es el talking head. ${ }^{10}$ Este formato, uno de los más tradicionales en la comunicación política, fue el segundo tipo de producción más utilizado (35; véase tabla 3). De acuerdo con nuestra investigación, la coalición de izquierda utilizó mayoritariamente los talking head para presentar a su candidato (PRD, 56\%; PT, 48\%; MC, 58\%), personalizando los mensajes políticos al establecer una relación directa entre el candidato, López Obrador, y los televidentes.

\section{Tabla 3 .}

Porcentaje de producciones por formato (documental, video clip, dramatización y talking head) y patrocinador (PAN, PRD y PRI) en los spots televisivos durante la elección federal de 2012

\begin{tabular}{|ccccccccc|}
\hline & \multicolumn{8}{c}{ P a trocinad o r } \\
\hline Formato & PAN & PRD & PRI & PT & PVEM & PANAL & MC & Total \\
\hline Documental & 38 & 28 & 66 & 37 & 44 & 29 & 29 & 46 \\
\hline Video clip & 4 & & 1 & & & 10 & & 2 \\
\hline Dramatización & 17 & 16 & 12 & 15 & 25 & 35 & 13 & 17 \\
\hline Talking head & 41 & 55 & 21 & 48 & 31 & 26 & 58 & 35 \\
\hline Total & 100 & 100 & 100 & 100 & 100 & 100 & 100 & 100 \\
\hline
\end{tabular}

Nota: El formato en cada spot se analizó según la siguiente definición:

Documental: un formato narrativo en donde se presenta información sobre un tema determinado y con la pretensión de utilizar dicha información como el elemento fundamental del mensaje.

Video clip: un video musical

Dramatización: Representación actuada en un escenario ficticio, basado en la realidad, que busca enfocar la atención en temas de interés para el presentador dominante.

Talking head: formato en el que una persona aparece hablando directamente al televidente dentro una toma fija que muestra la imagen de quien habla de los hombros hacia arriba.

Fuente: elaboración propia.

10 Formato en el que una persona aparece hablando directamente al televidente dentro una toma fija que muestra la imagen de quien habla de los hombros hacia arriba 
Finalmente es preciso destacar que los partidos "pequeños" utilizaron otros formatos como la dramatización ${ }^{11}$ y el videoclip. ${ }^{12}$ Por una parte, la dramatización fue el tercer formato utilizados en el proceso federal electoral de 2012 (17\%). En este sentido, destacan los casos del Panal y el PVEM, quienes dedicaron un cuarto o más de sus spots a dramatizaciones ( 25 y 35\%, respectivamente). Por otra, el videoclip fue el formato menos utilizado (2\%). En este sentido, el uso de videoclips, principalmente por el Panal, que destinó 10\% de sus producciones a este formato, se explica, en parte, como un método para reforzar simpatías por aquellas personas que ya tenían una opinión favorable del partido o en donde se buscaba posicionar a un candidato sin una trayectoria política previa (Gabriel Quadri de la Torre).

\section{Emotividad y racionalidad en las campañas}

El argumento de un spot determina el carácter fundamental del razonamiento (hechos, opiniones, argumentos, etcétera) empleado en la narración para probar o demostrar una idea. De acuerdo con los datos de la presente investigación, el uso de argumentos emocionales y racionales en los spots de los partidos políticos estuvo dividido prácticamente a la mitad ( $47 \%$ emocionales y $53 \%$ racionales). ${ }^{13}$

En la investigación se determinó (véase tabla 4) que a mayor profundidad en un tema, es decir, al contener información adicional o incluso planes de acción para solucionar un problema en particular, mayor racionalidad en el tipo de argumentos (53.2\% de los spots fueron racionales). Mientras tanto, a menor profundidad mayor grado de emotividad (46.8\% fueron emocionales).

11 Representación actuada en un escenario ficticio, basado en la realidad, que busca enfocar la atención en temas de interés para el presentador dominante.

12 Formato donde la música lleva la narrativa del mensaje.

13 En la investigación se prevén dos tipos de argumentos: emocional, cuando la información se sustenta en el carácter emocional de una narración subjetiva que apela primordialmente a una sensación y/o sentimiento (por ejemplo miedo, malestar, bienestar, humor, etcétera), y racional, cuando hay un discurso que hace uso, primordialmente, de datos objetivos y/o argumentos (propuestas) presentados al momento de dirigirse al televidente. 
De entre ellos cabe resaltar la publicidad del PVEM quien ha tenido como estrategia, tanto en 2006 como en 2012, la producción de spots con propuestas concretas en materia de política pública aunque comúnmente dichas propuestas son transmitidas mediante narrativas con un alto grado de emotividad (dramatizaciones). Sucedió con la pena de muerte en 2009 y ahora se pudo apreciar nuevamente con la iniciativa para el otorgamiento de vales de medicinas o penas para quienes contaminen los mantos acuíferos.

\section{Tabla 4 .}

Porcentaje de spots por enfoque del spot (un tema, forma de resolver y política pública) y tipo de argumento (emocional y racional) en los spots televisivos durante la elección federal de 2012

\begin{tabular}{|c|c|c|c|c|c|}
\hline & & \multicolumn{3}{|c|}{ Enfoque del spot } & Total \\
\hline \multirow{2}{*}{$\begin{array}{c}\text { Tipo de } \\
\text { argumento }\end{array}$} & Enocional & 62 & Rorma de resolver & Política Pública & \\
\cline { 2 - 6 } & Racional & 38 & 25 & 11 & 47 \\
\hline \multicolumn{2}{|c|}{ Total } & 100 & 75 & 89 & 53 \\
\hline
\end{tabular}

Nota: de acuerdo al manual de codificación, el tipo de argumento de cada spot se analizó según la siguiente definición:

Argumento de la proposición: categoría que determina el carácter fundamental del razonamiento (hechos, opiniones, argumentos, etcétera) que se emplea en la narración para probar o demostrar una proposición.

Emocional: cuando la información se sustenta en el carácter emocional de una narración subjetiva que apela primordialmente a una sensación, sentimiento... (por ejemplo: miedo, malestar, bienestar, humor, etcétera).

Racional: discurso que hace uso, primordialmente, de datos objetivos y/o argumentos (propuestas) que son presentados al momento de dirigirse al televidente.

Fuente: elaboración propia.

\section{Partidos como argumento persuasivo}

Otra de las principales modificaciones introducidas por la reforma de 2007-2008 es que cada partido político, esté o no coaligado con otro, obtiene sus votos directamente de la elección en la boleta electoral. De ello depende el refrendo de su registro. De acuerdo con la legislación 
vigente (Cofipe, artículo 95), los partidos políticos que compitan en coalición deberán aparecer con su denominación y emblema en la boleta electoral de forma individual. De hecho, los partidos políticos, en lo individual, desarrollan estrategias a partir de sus contenidos, buscando, principalmente, atraer el voto, incluso, en los casos en donde un mismo partido postula un mismo candidato. ${ }^{14}$

De acuerdo con nuestro estudio, las menciones explícitas ${ }^{15}$ a los partidos políticos fue de $67.7 \%$ (véase tabla 5), un porcentaje alto si se toma en cuenta que éstas tienden a estar más presentes en elecciones intermedias donde se promociona la marca-partido antes que a un candidato específico, por ejemplo, en la elección federal de 2009 la referencia a partidos políticos fue de $94 \%$ (Juárez, 2010).

\section{Tabla 5 .}

Porcentaje de referencias a partidos 'grandes' (PAN, PRD y PRI) y 'pequeños' (PT, PVEM, PANAL, MC) en los spots televisivos durante la elección federal de 2012

\begin{tabular}{|cccccccc|}
\hline & \multicolumn{4}{c}{ Partidos 'grandes' } & \multicolumn{3}{c|}{ Partidos 'pequeños' } \\
\hline Partido Político & PAN & PRD & PRI & PT & PVEM & PANAL & MC \\
\hline Ausencia & $\mathbf{8 4}$ & $\mathbf{1 0 0}$ & $\mathbf{9 7}$ & 63 & 12 & 32 & 16 \\
\hline Presencia & 16 & & 3 & 37 & $\mathbf{8 8}$ & $\mathbf{6 8}$ & $\mathbf{8 4}$ \\
\hline
\end{tabular}

Nota: de acuerdo al manual de codificación, la referencia al partido en cada spot se analizó según la siguiente definición:

Referencias al partido: referencia explícita, verbal o visual, dentro de la narrativa del mensaje, del partido que lo patrocina o del partido de cualquiera de sus oponentes. La presentación del logotipo del partido en el spot no es suficiente para catalogarlo como referencia.

Fuente: elaboración propia.

14 En la elección federal de 2012 compitieron por la Presidencia cuatro candidatos, una por el Partido Acción Nacional (Josefina Vázquez Mota), otro por el Partido Nueva Alianza (Gabriel Quadri de la Torre) y dos más por dos coaliciones, Andrés Manuel López Obrador por el Movimiento Progresista (PRD, PT, MC) y Enrique Peña Nieto por Compromiso por México (PRI y PVEM).

${ }^{15}$ Las menciones a los partidos políticos consisten en la referencia explícita, verbal o visual y dentro de la narrativa del mensaje, del partido que lo patrocina o del partido de cualquiera de sus oponentes. La presentación del logotipo del partido en el spot no es suficiente para catalogarlo como referencia. 
Esto se debe, entre otras cosas, a la necesidad de los partidos "chicos" de posicionar la marca-partido entre el electorado pues de ello depende el refrendo de su registro. Resalta el hecho de que los partidos integrantes de la coalición de izquierda utilizaron las mismas producciones audiovisuales, pero tanto el PT como MC las intervinieron para posicionar su logos y lemas a lo largo de la narrativa central, que casi siempre se enfocó en el candidato de la coalición.

\section{Conclusiones}

Con base en los datos antes expuestos, es posible listar una serie de conclusiones respecto a los efectos de la reforma electoral 2007-2008 en el uso del spot publicitario como herramienta de comunicación política en las elecciones federales de 2012.

Primero, la evidencia empírica apunta que el nivel de información política presentada por los partidos políticos en su publicidad es escaso y, cuando llega a aparecer, superficial. Uno de los hallazgos más importantes de la investigación es que más de la mitad de las producciones audiovisuales realizadas por los partidos políticos no se refieren a ningún tema que los mismos partidos postulan en su plataforma electoral. En este sentido, es posible inferir que el electorado que recibe la información de los spots políticos se entera más de los atributos y defectos personales de los contendientes, que de información política referente a los principales retos y problemas que enfrenta la sociedad y los posicionamientos concretos de los candidatos frente a ellos. De hecho, aun cuando los partidos tratan alguno de los temas de interés público en sus spots, lo hacen de manera dispersa y poco propositiva. Es raro encontrar casos en donde los partidos políticos aborden temas de interés público de forma profunda, con cierta especificidad y con propuestas orientadas a diferenciar sus plataformas a partir de políticas públicas.

Segundo, a partir de la reforma electoral 2007-2008 se percibe una disminución de las campañas negativas y de contraste aunque esto no se ha traducido en la generación de piezas de publicidad política más informativas. De acuerdo con los datos de esta investigación han aumentado los spots políticos de promoción que resaltan características insustanciales de los candidatos de manera unilateral. Como lo 
demuestra el análisis de contenido de esta investigación, estos spots se caracterizan por privilegiar un monólogo antes que una conversación. El objetivo central es ganar simpatías más que confrontar ideas. Por tanto, en los spots de la elección federal 2012 hay una ausencia de producciones con contenido sustancial, así como de referencias explícitas a las plataformas programáticas propias o de otros partidos políticos.

Tercero, la publicidad política televisiva favorece la personalización de la política en detrimento de la difusión de plataformas electorales y propuestas que diferencien la oferta política de los contendientes. Los datos presentados en este estudio advierten que los partidos políticos utilizan la publicidad política para, principalmente, promover la imagen de sus candidatos a la Presidencia. Este fenómeno fomenta la personalización de lo político en donde los candidatos presidenciales se convierten en el eje y sustancia de la campaña electoral para renovar los escaños del Congreso de la Unión. La personalización observada en los spots de la campaña presidencial de 2012 deja de lado la discusión de información política útil y necesaria para el electorado.

Cuarto, la legislación electoral establece una distribución del tiempo aire entre la campaña a presidente y aquellas con miras a renovar el Congreso de la Unión, en donde cualquiera de ambos poderes debe obtener un mínimo del 30\% de los mensajes. Nuestro análisis da cuenta de que 8 de cada 10 spots fueron producidos para promover a los candidatos a la Presidencia reduciendo así la presencia de las campañas al Senado y a la Cámara de los Diputados en la publicidad política de los partidos. Ello da cuenta de procesos electorales predominantemente presidencialistas en donde el Poder Legislativo parecería, en materia de comunicación política, quedar marginado de la exposición publicitaria de acuerdo al actual modelo de comunicación política.

Por último, los argumentos emocionales son los más utilizados por los partidos políticos. De acuerdo con los datos de esta investigación la gran mayoría de los spots utilizan enunciaciones emocionales y no premisas racionales ni fácticas. Aunque la evidencia señala que este tipo de construcciones emotivas representan la gran mayoría, los hallazgos de este estudio también apuntan que aquellos temas de los que sí se tratan de apropiar los partidos políticos se abordan preferentemente con una estrategia racional. Es decir, los datos generados en esta investigación arrojan que los pocos temas desarrollados ampliamente por los partidos políticos (i. e. el PVEM sobre "política ambiental", el PRI sobre "política económica", etcétera) se presentan con mayor 
profundidad y con base en una estrategia racional. La especificidad de un tema junto con la racionalidad de su tratamiento promueven información política de mayor utilidad para los electores.

El presente diagnóstico llama a un replanteamiento en la manera en la que el IFE administra el tiempo aire durante los procesos electorales. Si bien consideramos que la reforma electoral 2007-2008 avanzó positivamente al prohibír la contratación de publicidad en radio y televisión creemos que el paso siguiente es garantizar una utilización más eficaz de este espacio radioeléctrico de difusión. Hacerlo beneficiaría al ciudadano si, y solo si, la información que por estos espacios se difunda contenga elementos sustantivos de información que permitan contrastar ideas, diagnósticos y propuestas partidistas. Ese debe ser el siguiente paso al afinar un modelo de comunicación política dentro de un sistema de financiamiento público, como el hoy vigente, que obliga a los partidos a servir a un interés superior que la simple promoción persuasiva de sus candidatos. Sobre todo si esa es la principal justificación tras la prerrogativa para acceder gratuitamente a la radio y la televisión.

\section{BIBLIOGRAFÍA}

Ansolabehere, S. e Inyegar, S., 1994, "Riding the wave and claiming ownership over issues. The joint effects of adverstising and bews coverage in campaigns", Public Opinion Quarterly, vol. 58.

-_- 1995, Going Negative: How Attack Ads Shrink and Polarize the Electorate, Nueva York, Free Press.

Guerrero, Manuel y Arellano, Marco, 2012, Campañas negativas en 2006 ¿Cómo afectaron el voto?, México, Universidad Iberoamericana.

Freedman, Paul y Goldstein, Ken, 1999, "Measuring Media Exposure and the Effects of Negative Campaign Ads", American Journal of Political Science, vol. 43, núm. 3.

JuÁrez GÁmiz, Julio, 2007, "Mirando las elecciones presidenciales del 2006 a través de los spots de campaña”, Revista Espiral de la Universidad de Guadalajara, vol. XIV, núm. 40. 
- - , 2009, La televisión encantada. Publicidad política en México, México, UNAM, Centro de Investigaciones Interdisciplinarias en Ciencias y Humanidades.

- - - 2010, "El papel de la publicidad política en la nueva ley electoral: una mirada crítica", Revista Sociológica de la Universidad Autónoma Metropolitana, núm. 72.

Treviño, Javier, 2009, "Pánico moral en las campañas electorales de 2006: la elaboración del 'peligro para México"', Revista Foro Internacional, vol. XLIX, núm. 3.

\section{Encuestas}

BGC-Excélsior, 23 de abril de 2012. Encuesta nacional.

Consulta Mitofsky, 1 de mayo de 2012. Encuesta nacional.

Reforma, 29 de agosto de 2010. Encuesta nacional.

- - - 25 de abril de 2012. Encuesta nacional.

-_-, 22 de marzo de 2012. Encuesta nacional.

- -, 1 de mayo de 2012. Encuesta nacional.

- -, 31 de mayo de 2012. Encuesta nacional.

- — 2 de junio de 2012. Encuesta nacional.

\section{Otros documentos}

Resultados de la encuesta poselectoral realizada por el Centro de Investigación y Docencia Económicas, 13 de octubre de 2009, Encuesta nacional.

Constitución Política de los Estados Unidos Mexicanos. http://www. diputados.gob.mx/LeyesBiblio/pdf/1.pdf.

Código Federal de Instituciones y Procedimientos Electorales http:// info4.juridicas.unam. mx/ijure/tcfed/4.htm. 